\title{
Renal involvement in tuberous sclerosis complex
}

Dear Editor,

I think that the research article published in Volume 50 , issue 1, 2015 in your journal between the pages of 51 and 60 titled "Tuberous sclerosis complex; a single center experience" written by Erol et al. (1) is an important article in terms of emphasizing awareness of this clinical condition. Tuberous sclerosis is a rare disease with genetic inheritance which may involve any organ system. As stated in the international diagnostic criteria, the importance of physical examination can not be denied in the diagnosis of tuberous sclerosis complex. Recognition of specific lesions including hypomelanotic macules ( $>3)$, Shagreen patch, forehead plaque, non-traumatic fibromas around nails and adenoma sabaceum (angiofibromas on the face) which can be identified on examination of the skin should suggest tuberous sclerosis $(2,3)$. Renal or lung involvement is observed more commonly in the adult patient group. Renal involvement is present in $50-80 \%$ of all patients (4). Renal involvement is most commonly manifested by angiomyolipomas. Presence of bilateral and multiple angiomyolipoma especially in the kidney on imaging is a significant clue. Massive hemorrhage which develops suddenly may require an urgent approach. Nephrectomy may be needed or hemorrhage may result in exitus. Patients may present with end stage renal disease in the adulthood. There is a risk of development of renal cell carcinoma $(\sim \% 1)$ and oncocytoma, albeit low. Presence of rapid growth in renal lesions, calcifications and central necrosis should raise suspicion in terms of malign transformation (5). The finding that there was no malignancy in the study of Erol et al. (1) may be related with the fact that the study was conducted with children. Signs including bloody urine and side pain should be absolutely evaluated in this patient group.
In conclusion, recognition of skin lesions by good inspection will allow physicians to make a diagnosis of tuberous sclerosis and enable nephrologic follow-up of these cases. Renal function tests should be monitored, hypertension should be controlled and renal lesions should be monitored by radiological imaging regularly. Renal involvement is the second cause of death after central nervous system disorders in the childhood and the first cause of death in the adulthood (6). This retrospective study of Erol et al. (1) is important in terms of raising awareness and clinical suspicion. I thank the authors and you for this nice article.

\section{References}

1. Erol İ, Savaş T, Şekerci S, et al. Tuberous sclerosis complex; single center experience. Turk Pediatri Ars 2015; 50: 51-60. [CrossRef]

2. Alp A, Sezer SD, Tanrisev M. Tuberous sclerosis diagnosed in adult age. Pak J Med Sci 2011; 1: 208-11.

3. Arbiser JL, Brat D, Hunter S, et al. Tuberous sclerosis-associated lesions of the kidneys, brain and skin are angiogenic neoplasms. J Am Acad Dermatol 2002; 46: 376-80. [CrossRef]

4. O'Callaghan FJ, Noakes MJ, Martyn CN, Osborne JP. An epidemiological study of renal pathology in tuberous sclerosis complex. BJU Int 2004; 94: 853-7. [CrossRef]

5. Rouvière $\mathrm{O}$, Nivet $\mathrm{H}$, Grenier N, Zini L, Lechevallier E. Kidney damage due to tuberous sclerosis complex: Management recommendations. Diagnostic and Interventional Imaging 2013; 94: 225-37. [CrossRef]

6. Sheperd CW, Gomez MR, Lie JT. Causes of death in patients with tuberous sclerosis. Mayo Clin Proc 1996; 66: 792-9. [CrossRef]

\section{Alper Alp}

Clinic of Nephrology, Van Regional Training and Research Hospital, Van, Turkey 